\title{
Correction to: Responding to COVID-19: What's the Problem?
}

\section{Roderick J. Lawrence}

\section{Correction to: Journal of Urban Health (2020) https://doi.org/10.1007/s11524-020-00456-4}

The following corrections should be noted to this article. The first sentence of the second paragraph should read as follows:

Several types of resources coexist for coordinated action and systemic responses to this extraordinary situationadministrative, behavioural, financial, health care, legal and medical resources-that have been used at different geo-political levels, sometimes in an uncoordinated fashion of 'winner takes all'.

In the caption to Fig. 1, the "1" before "Effective responses" should be deleted.
In the last sentence of the third full paragraph of the third page of the article, "actions initiatives" should read "actions and initiatives".

Finally, the penultimate sentence of the last paragraph of the article should read as follows:

Likewise, the absurdity of the request for social distancing by staying 'at home' given that not less than 150 million people are declared homeless and 1.6 billion are estimated to live in inadequate housing [9].

Publisher's Note Springer Nature remains neutral with regard to jurisdictional claims in published maps and institutional affiliations.
The online version of the original article can be found at https://doi.org/10.1007/s11524-020-00456-4

R. J. Lawrence $(\bowtie)$

Geneva School of Social Sciences (G3S), University of Geneva, Geneva, Switzerland

e-mail: roderick.lawrence@unige.ch 